\title{
Title: Active commuting to school in Portuguese adolescents: Using PALMS to detect trips.
}

\author{
Author Details: \\ Andreia Nogueira Pizarro ${ }^{1 凶}$, Jasper Schipperijn ${ }^{2}$, Henriette Bondo Andersen ${ }^{2}$, José Carlos \\ Ribeiro ${ }^{1}$, Jorge Mota ${ }^{1}$ and Maria Paula Santos ${ }^{1}$ \\ 1 CIAFEL - Research Centre in Physical Activity, Health and Leisure, Faculty of Sports, \\ University of Porto, Portugal \\ ${ }^{2}$ Research Unit for Active Living, Department of Sport Science and Clinical Biomechanics, \\ University of Southern Denmark, Odense, Denmark
}

$\square$ : Corresponding author

Andreia Nogueira Pizarro

Research Centre in Physical Activity, Health and Leisure

Faculty of Sport, University of Porto

Rua Dr. Plácido Costa, 91, 4200-450 Porto, Portugal

Phone: +351 225074785, Fax: +351225500689

e-mail: andreia.pizarro@gmail.com

\section{Email adresses:}

ANP: andreia.pizarro@gmail.com

JS: jschipperijn@health.sdu.dk

HBA: hbandersen@health.sdu.dk

JCR: jiibeiro@fade.up.pt

JM: jmota@fade.up.pt

MPS: msantos@fade.up.pt 


\section{Abstract}

The declining levels of physical activity (PA) have led to active commuting to school (ACS) being seen as a key strategy to increase PA levels in school-aged children. In Portugal, no data exists on the patterns of this behavior, an essential step for developing evidence-based and effective interventions.

The purpose of this study is to explore the travel to school behavior using an objective methodology.

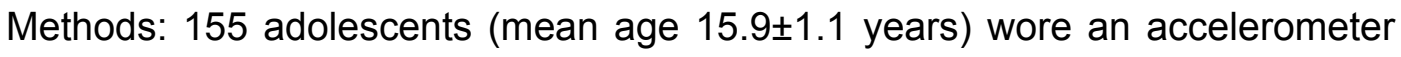
and a GPS for 7 consecutive days. Home and school addresses were geocoded to identify home-school trips. The web-based tool PALMS was used to combine GPS and accelerometer data, categorize Moderate to Vigorous Physical Activity (MVPA) and classify trip mode of home-school trips into: walking, bicycling or vehicle.

Results: 609 trips were identified as home-school trips. Walking was the most frequent trip mode (68.8\%) whereas bicycling was less common $(14.4 \%)$. Median home-school walking trip length was $0.9 \mathrm{~km}$ and $96.7 \%$ of the trips were under $2.0 \mathrm{~km}$. Near $80 \%$ of the total walking trip time(to or from school) was in MVPA and contributed on average with $12( \pm 5.6)$ minutes to daily recommendations. Differences were found whether the trip started at home or at school, walking school-home trips took longer and had more minutes in MVPA than home-school trips. Regression analyses showed increasing distance to be associated with lower odds of ACS in boys (OR: 0.32; 95\% Cl: 0.16-0.63) and girls (OR: 0.10; 95\% Cl: 0.04-0.25).

Conclusion: Walking to school and back home can contribute with up to $40 \%$ of recommended daily MVPA, so increasing this behavior may be of particular relevance to increase PA levels. On the other hand, cycling is underused in home-school trips and strategies to promote the use of bicycle could also be of interest, especially in trips longer than $2.0 \mathrm{~km}$. 
KEY-WORDS: Active travel; GPS; means of transport; distance; adolescents; physical activity 


\section{INTRODUCTION}

Active commuting to school (ACS) has been proposed as a potentially source of physical activity (PA) in children and adolescents (Chillon et al., 2010; Davison et al., 2008) and can represent 20 to $30 \%$ of daily moderate to vigorous physical activity (MVPA) (Klinker et al., 2014; Southward et al., 2012). With decreasing levels of physical activity in children and adolescents, ACS due to its regular nature, is likely to be a key element for children's health (Pizarro et al., 2013; Tudor-Locke et al., 2001) and interventions to encourage ACS are becoming a priority in some countries (Active Healthy Kids Canada, 2013; National Safe Routes to School Taskforce, 2008). However, most research on transportrelated physical activity (PA) relies on self-reported data and geographic information systems (GIS) based estimates of routes taken, which are not always representative of actual routes (Duncan and Mummery, 2007). Thus, comparing results across studies should be done with caution as discrepant methods are commonly used to access and classify ACS (Sirard and Slater, 2008).

Global position system (GPS) tracking used in combination with accelerometer data, is arising as an objective approach to assess means of transport and reduce self-reporting bias (Feng and Timmermans, 2013; Kerr et al., 2011). Moreover, as several built environment features that may be related to ACS were identified (Pont et al., 2009), the joint use of GPS data and GIS can inform researchers about the real exposure to these different environments. Despite the advantages advocated by this new approach, data processing emerges as a challenge due to the large size and complexity of this type of data. Novel and robust methods are requested to improve the investigation on the relationship between PA and environment (McCrorie et al., 2014). The Personal Activity Location Measurement System (PALMS) is a web-based application capable of integrating and processing activity and location data in a relatively simple way and may be the key to unify methods and allow for comparison of results helping in clarification of findings in this field (https://ucsdpalms-project.wikispaces.com/). 
Similar to countries like the United States (McDonald, 2007) or United Kingdom (Black et al., 2001), Portuguese transportation statistics reveal an alarming drop of $54 \%$ in active commuting in the general population in the last 10 years. Despite being scarce, data for ACS in Portugal shows that only around half of the students use active transportation (Cooper et al., 2005; Mota et al., 2007) and reveals a huge potential for interventions to increase physical activity. While evidence suggest that ACS is influenced by country specific environmental and cultural factors (Faulkner et al., 2009), little is known about Portuguese adolescent's mode of travel to school, distance and time travelled. Therefore, in order to provide a more complete description of the daily transport patterns, using data from GPS and accelerometer, our main aims were: 1) determine the characteristics of the journey between home and school; 2) analyze it's contribution to achieve physical activity guidelines; 3) analyze the relationship between distance travelled to school and transportation mode.

\section{METHODS}

Three public secondary schools from Porto County were selected to participate in this study. In order to maximize environmental variability, we've randomly selected one school near the beach, one near the city center and one in the suburbs. To be eligible, students needed to participate in physical education classes (mandatory within the Portuguese Educational System), and report an absence of physical and mental health problems. Both participants and their parents received a complete explanation of the purpose of the investigation and in the case of a positive participation, signed a written consent to participate in the study After excluding respondents with missing accelerometer and GPS data, the final sample consisted of 155 adolescents (55\% females) between 14 and 18 years (mean age 15.9 \pm 1.1 years old). Data from participants with at least one home-school-home journey were included in the analyses. Participants provided a voluntary written consent from their parents to participate in this study. Data were confidential and were collected between February 2013 and May 2014. Ethical approval for this study was obtained from the Faculty of Sports ethics committee, the Portuguese Foundation for Science and Technology and from the regional section of the Ministry of Education. 


\section{MEASUREMENTS}

Physical Activity: Physical activity was measured using Actigraph accelerometers, model GT3X+ (Actigraph, Pensacola, FL). Accelerometers were initialized to collect $30 \mathrm{~Hz}$ and Actilife software was used to initialize and download devices, and compile the RAW data to 30 second epochs. Evenson cut-points were used to categorize MVPA (2296 counts/min) (Evenson et al., 2008) as they seem to exhibit significantly better accuracy than others in children and adolescents (Trost et al., 2011).

Positional data: were recorded every 15 seconds using a Qstarz BT-Q1000XT Travel Recorder. Besides a high accuracy under various environmental conditions and good signal acquisition time (Duncan et al., 2009), this device also showed an acceptable dynamic accuracy during different modes of transportation, in different environments. The median error during walking trips was $3.9 \mathrm{~m}, 2.0 \mathrm{~m}$ for bicycle trips, $1.5 \mathrm{~m}$ for bus and $0.5 \mathrm{~m}$ for car (Schipperijn et al., 2014).

GPS and Accelerometer Protocols: Participants were requested to wear the accelerometer and the GPS device attached to an elastic belt and placed on opposite sides of their waist for 7 consecutive days. Children were trained to switch on and off and to charge the GPS monitors overnight. Instructions were given to wear the monitors all times except when sleeping, bathing, swimming or other water activities.

The Personal Activity Location Measurement System (PALMS) (https://ucsdpalms-project.wikispaces.com/) was used for Data processing and analyses. First, PALMS used distance and speed between GPS points to classify whether each epoch was part of a trip and the trip mode based on the following protocol:

- groups of sequential fixes ( $\geq 2$ minutes) were considered trips if they spanned $\geq 100$ meters with an average speed of $\geq 1.5 \mathrm{~km} /$ hour

- pauses of up to 3 minutes were allowed during a trip to account for circumstances such as stop lights

trips were classified into Walking trips if they had a $90^{\text {th }}$ percentile speed of $<10$ $\mathrm{km} / \mathrm{hour}$; trips with a 90th percentile speed between 10 and $35 \mathrm{~km} / \mathrm{hour}$ were classified as bicycling trips and trips were considered vehicle trips if they had a $90^{\text {th }}$ percentile speed of $\geq 35 \mathrm{~km} / \mathrm{h}$ (Carlson et al., 2014). points estimated to be 
indoors were removed from the starts and ends of trips. Indoor detection was based on a maximum value of signal to noise ratio of 225 and a maximum satellite ratio of 50 .Second, PALMS processed accelerometer data based on Evensons' cut points and a non-wear time definition of 60 minutes of consecutive zeros (Evenson et al., 2008). Finally, data was processed to produce a 30 second aggregated dataset with the information from both monitors.

School and participant's home addresses were then geocoded. A school was defined as the parcel on which the geocode point fell, while a $25 \mathrm{~m}$ Euclidean buffer was applied to participants' home address point to account for signal errors. Afterwards, a PostgreSQL database was built to combine the PALMS dataset with GIS data to identify trips that started at school and ended at home and vice-versa.

Anthropometric measurements were taken with adolescents in bare feet and lightly dressed. Height $(\mathrm{cm})$ was measured with SECA 206 Bodymeter Measuring Tape (SECA, Hamburg Germany) and weight $(\mathrm{Kg})$ was assessed using digital scales (TANITA BF-522 W, Tokyo, Japan). Participants body mass index $(\mathrm{BMI})$ was calculated as weight $(\mathrm{kg}) / \mathrm{height}(\mathrm{m})^{2}$. Adolescents were then categorized into 'normal weight' or 'overweight' (including obese) according to age- and sex-specific cut-off points for children (Cole et al., 2000).

Demographic data was obtained through a questionnaire including information on birth date, home address and gender.

\section{STATISTICAL PROCEDURES}

Data was analysed using IBM SPSS Statistics (version 21; SPSS, Inc., Chicago, IL). Significance level was set at $5 \%(p<0.05)$. Descriptive statistics were used to characterize the sample. For the purpose of this paper the analysis were conducted by trip instead of by participants. To analyse the relationship between distances travelled to school and transportation mode, we used a random intercepts mixed effects regression model to account for the nested structure of the data (trips within persons). Schools were included as fixed effect due to the limited number of schools participating. Due to large differences between boys and girls, we conducted analyses stratified by sex to 
ascertain the effects of distance, age, body mass index (BMI), number of trips per person and school on the likelihood to active commute to school. To interpret the variation of trips within the participants an intraclass correlation coefficient (ICC) was calculated by sex.

\section{RESULTS}

Sample characteristics and overall trips

Descriptive data for the demographic characteristics of the sample and overall trips detected can be found in Table 1. (INSERT TABLE 1)

A total of 7220 trips were identified with a median length of 678.2 meters and a median duration of 6.5 minutes. From these trips, $73.6 \%$ (5312) were active trips (walking and bicycle) while $26.4 \%$ (1908) were passive. The longest active trip detected was 4439.3 meters.

Walking was the preferred mode of travel in our sample (57.6\%) while only $16 \%$ of all trips detected were done by bicycle. As expected, walking trips were used for shorter distances (mean $0.5 \mathrm{~km}$ ) while motorized vehicle trips were considerably longer (mean $5.8 \mathrm{~km}$ ). During weekend days a 20\% drop in walking trips was observed while the number of vehicle trips increased (Figure 1). Home-school-home trips constituted $9.5 \%$ of the total number of active trips. Looking at participants instead of trips we found that $64 \%$ of the adolescents used active transport to school during most school days. (INSERT FIGURE 1)

Journey between home and school

$60.7 \%$ of the adolescents had valid GPS information for at least one of their home-school-home journeys. A higher proportion of females had valid data on home-school trips (61 vs $39 \% \quad p=0.000)$ when compared to males. No differences were found between adolescents with valid vs invalid data on homeschool-home trips in age or BMI.

On average participants recorded 7 trips between home and school. The most frequently used travel mode was walking (68.8\%), followed by vehicle $(16.7 \%)$ and bicycle (14.4\%). Median walking trip length between home and school was $0.9 \mathrm{~km}$, with the longest walking trip being $3.4 \mathrm{~km}$. For walking home-school trips the mean time spent in MVPA was $12 \pm 5.6$ minutes, i.e. $78 \%$ of the total trip time and representing $20 \%$ of recommended guidelines of 60 minutes of MVPA. 
This Further characteristics of the school journey are provided in Table 2. (INSERT TABLE 2)

\section{Distance travelled by transportation mode}

As illustrated in figure 2, almost all of the walking trips to/from school (96.7\%) were within $2.0 \mathrm{~km}$. Similarly, bicycle trips occurred mostly (92\%) within $2.0 \mathrm{~km}$. Of the vehicle trips $80.7 \%$ were within $3.5 \mathrm{~km}$ and $96.4 \%$ within $5.0 \mathrm{~km}$. (INSERT FIGURE 2)

After the first $\mathrm{km}$ as distance increases, the number of walking trips decreases and are replaced by an increasing number of vehicle trips, as expected. Journeys longer than $4.5 \mathrm{~km}$ are exclusively made by vehicle while in trips under $0.5 \mathrm{~km}$ no vehicle trips were observed and at $1.0 \mathrm{~km}$ only a small percentage of vehicle trips were observed (3.3\%). Bicycle trips were observed within a $4.5 \mathrm{~km}$ range.

Direction of the trip

As home to school and school to home trips usually don't take place at the same times of the day, meaning diverse environmental context (social, traffic, day-light), differences between trip direction were tested. Significant differences in minutes in MVPA and duration were found whether the trip started at home or at school (Table 3). (INSERT TABLE 3)

When walking was the mode of transportation, home to school trips took longer and had more minutes in MVPA than the school to home trips. Minutes spent in MVPA during the trips were also different for bicycling and vehicle however in those cases the home to school trip contributed with more time in MVPA.

Despite walking was the dominant mode of transportation in both directions, a significant $16 \%$ increase in walking trips was found for school-home trips when compared to home-school trips (Figure 3). (INSERT FIGURE 3)

Correlates of transportation mode 
For each additional $\mathrm{km}$ in trip distance there was a $68 \%$ decrease in the odds of active commuting in boys (OR: $0.32 ; 95 \% \mathrm{Cl}: 0.16-0.63$ ) and a $90 \%$ decrease in odds of active commuting in girls (OR: $0.10 ; 95 \% \mathrm{Cl}: 0.04-0.25)$. The ICC was $1.2 \%$ for girls and $8 \%$ for boys. (INSERT TABLE 4 )

\section{DISCUSSION}

Our study was one of the first using objective methods to classify trip modes in home-school journeys and measuring the actual route distance. To date most studies have relied on less accurate methods.

Our results showed that walking was the most frequent (68.8\%) means of travel in home-school trips. Although a higher percentage was found, this result is in line with another European study that reported walking as main mode used in $44.8 \%$ of home-school trips followed by cycling (34.6\%) (Dessing et al., 2014). On the other hand, a Belgian investigation, centered on participants instead of trips, observed that only $6.6 \%$ of the adolescents walked to school while $51.8 \%$ cycled there (Van Dyck et al., 2010). Despite the different walking percentages, active transportation was the main mode to get to school in these studies supporting previous research (Chillon et al., 2010; Santos et al., 2009). In contrast, motorized transport in home-school journeys was the most used method of transport in the US (Centers for Disease Control and Prevention, 2002), Australia (Harten and Olds, 2004) and even in UK (Department for Transport, 2014) where distances to school are usually longer than in most European countries (2008). For example, in Portugal, schools are built so the optimum distance one should live from school is $1.5 \mathrm{~km}$ or 30 minutes walking time, and the maximum distance is $2.2 \mathrm{~km}$ or 45 minutes walking time (Departamento de Avaliação Prospectiva e Planeamento, 2000). In our sample $50 \%$ of the participants lived within the optimum distance to school $(1.5 \mathrm{~km})$ while $72 \%$ lived within $2.2 \mathrm{~km}$, with a mean distance between home and school of $2.1 \mathrm{~km}$.

In line with this premise, our findings revealed that $96.7 \%$ of walking school journeys occurred within $2.0 \mathrm{~km}$ as well as $92 \%$ of cycling trips. So it is likely that in Portuguese adolescents the criterion and reasonable maximum distance 
for walking to school is $2.0 \mathrm{~km}$. This finding is consistent with study by Van Dyck et al. (2010) and in line with study by Nelson and Woods (2010). In our opinion, it seems that studying correlates of walking to school should be done within this distance removing it as a potential confounder. And intervention efforts to increase walking should target students living within this distance.

One possible explanation for the $2.0 \mathrm{~km}$ distance criterion found can be the urban planning policies mentioned above. This could be the evidence needed for authorities to replicate this school siting policies in other settings for ACS proliferation. Another example is a study from the Netherlands, were the average distance to an elementary school was smaller than $2.0 \mathrm{~km}$, which showed that $79 \%$ of the trips to school were made by active (Dessing et al., 2014).

On the other hand, our finding for cycling distances $(2.0 \mathrm{~km})$ is not in agreement with results of Belgium study $(8.0 \mathrm{~km})$ conducted by Van Dyck et al. (2010) and Irish study $(4.0 \mathrm{~km})$ conducted by Nelson and Woods (2010). The difference might be due to difference in the built environment, e.g. Porto is quite hilly, and a closer look at the built environment in these three cities might help explain the differences; further research into this is needed. Another possible reason may be related to cycling not being a particular popular means of travel in Portugal, especially in the northern region (Instituto Nacional de Estatistica, 2012). In fact, until 2014 cyclists were required by traffic laws to cycle on the roadside that often has bad pavement conditions as uneven ground, holes, rocks, and other obstacles affecting the stability and traction of the bicycle and forcing cyclists to regular path deviations (Núcleo de Estudos e Planeamento, 2014). Moreover cycling was considered unsafe as the probability of suffering a severe or fatal injury was four times greater than driving a car. This was because cyclists didn't have any road priorities or laws protecting them, they weren't considered as vulnerable users and for example cars didn't have to slow down next to them (Núcleo de Estudos e Planeamento, 2014). Despite a possible overestimation (see in limitations of the study), only $8 \%$ of the school trips made by bike were over $2.0 \mathrm{~km}$. According to other studies, that leaves an opportunity for increasing ACS in our population by encouraging more young people to cycle for a distance of up to 4.0 or $8.0 \mathrm{~km}$. In order to increase ACS, policies that 
remove barriers and promote the conditions necessary for choosing active modes of transportation are needed (Cooper et al., 2010; Jensen, 2008). These may include: 1) cycling-friendly infrastructures like separate bike lanes, traffic calming measures, car free zones; 2) bike parking and end of the trip facilities such as showers, bicycle stations, bike lockers; and 3) legal interventions as speed limits (Pucher et al., 2010). Moreover, research identified policies to increase walking and bicycling as an effective way of improving the safety of people involved in these behaviors. As more people walk or bicycle the less likely any of them are to be injured. The most likely mechanism which underlies safety for cyclists and walkers is modification of motorists behavior as this influences the likelihood of collisions (Jacobsen, 2003).

In Portugal, only in January 2014 an established law ended the obligation to cycle on the roadside (sometimes non existing) and allowed bikers to take their place on the roads as any other vehicle (2013), giving them vehicle priorities in order to promote safer bicycle riding and increase the rates of this behavior. This can be a turning point in the transportation system and further research is needed to understand the implication of this modification on rates of active transport to school for children and adolescents.

More minutes in MVPA were recorded during walking trips compared to during vehicle trips, as expected. In fact most of the walking trip to/from school time (78\%) was in MVPA. An average of 12 minutes, corresponding to $20 \%$ of recommended daily MVPA, were observed during walking trips while vehicle trips only represented $2 \%$. Moreover, trips to/from school were significantly faster $(4.15 \mathrm{~km} / \mathrm{h}$ vs $3.08 \mathrm{~km} / \mathrm{h}$ ) than trips to other destinations (data not shown). This observation emphasizes the meaningful role that the trip to school may play in youth achieving recommended PA guidelines, and the associated potential for achieving health benefits. So, strategies aimed to increase this behavior are a relevant approach for increasing physical activity levels. To our knowledge only two other studies objectively accessed time spent in MVPA during a walking trip to school among adolescents. Similar to our results Southward et al. (2012) observed approximately 11 minutes of MVPA during home-school trips, while in the study by Voss et al. (Voss et al., 2014) walking trips only contributed with $9.2 \mathrm{~min}$ of MVPA on average. Interestingly, the 
results by Voss et al. were comparable to ours in terms of distance and duration of the walking trips. Differences in time in MVPA during school trips may be related to features of the built environment, for example slope, and further research is needed.

Significant differences between trips to school and from school were found, with more active transport taking place during the school-home trip. One may speculate that these differences could be related to the pressure youth are submitted to get to school on time, first at home and due to the traffic congestion also during their trip to school. Longer trip duration and more time spent in MVPA during school-home walking trips may be related to the absence of a schedule to accomplish allowing adolescents to spent more time on the trip. It may also be that adolescents travel home with friends and may be involved in some kind of play during these trips. A significant higher rate of walking was found for school-home trips when compared with home-school trips. Although only few studies looked at this difference, similar results were found by other researchers (Larsen et al., 2009; Schlossberg et al., 2006) taking us to believe that this is may be a common trend. Explanations for this trend are usually related to the parental time schedule that allows parents to drive their children in the morning, while they are usually at work when their children leave school. Therefore, on one hand opportunities may exist to increase ACS on the homeschool trip; on the other hand more attention should be given to the schoolhome trip when studying the relations between environmental features and active transport.

Finally, although the variation of trips within the participants was higher in boys that in girls, according to our results larger distances are likely to increase the odds of motorized travel in both boys and girls. In fact, distance is the strongest environmental predictor of school travel mode choice (Wong et al., 2011). As changing school locations is unlikely in most countries, the implications of this finding include increasing the number of households within $2.0 \mathrm{~km}$ of the schools (i.e. urban densification), building new schools closer to where students live, and more feasible interventions like changing traffic directions, building paths, connecting public transport and other travel planning practices that enable more direct routes to school shortening the home-school distance. 
Moreover, as no significant associations between the probability of active commuting to school and BMl or age were found one can suggest that increasing ACS may be a simple and effective strategy to help increase PA levels particularly for overweight adolescents that usually have less PA opportunities.

This research contributes to increase the understanding of geographical variation of the relation between the environment and active transportation. Strengths of this study include the use of objective measures of activity and location that were automatically combined to assess trips to school and classify trip mode. This methodology reduces common bias of self-reporting and measures the actual route taken between home and school, instead of common approximations such as Euclidean distances and shortest route approaches. Moreover, all trips between home and school are included and not only trips before and after school, i.e., trips over lunch time are also included.

Integration of acelerometry and GPS data is a relatively new and not enough is known about the optimal methods for manipulation of this type of data. In fact, no consensus exist for guidance in dealing with these type of data issues (McCrorie et al., 2014). However, PALMS is a free, simple and intuitive software that may be particularly helpful in future research as it uses several methods to reduce the error in data, allowing researchers to manipulate protocols and quickly processes the complex datasets.

This study has some limitations that should be mentioned. The three schools were selected to increase environmental variation in the sample and may not represent the population, therefore limiting the generalizability of our findings. However, the results found provide a significant advancement in the unknown field of active commuting to school behavior among Portuguese adolescents, which will help inform future research and physical activity interventions. GPS signal acquisition time when leaving school and home buildings might have influence the number of trips included in our study as the first data point may have occurred outside the inclusion criterion distance. Trip underestimation may also have occurred if journeys had intermediate stops longer than 5 minutes as our inclusion criteria did not account these trips as home-school trips. Exploring 
pause time is therefore recommended for future studies particularly in school to home trips, where children have more freedom to explore their environment. Other valid explanations for trip underestimation could be related with children not wearing one or the two devices all times, children could have missed school, and also devices mal functioning.

The objective method used to categorize trips is based on GPS-derived travel speeds and may be, in our particular context, an overestimation of cycling trips. Despite, previous studies found a 73\% agreement between PALMS bicycling and sensecam trips (Carlson et al., 2014) few adolescents from our sample selfreported cycling (data not shown). Moreover, unlike in the US were bus average speed is around $21.0 \mathrm{~km} / \mathrm{h}$ (American public transportation assotiation, 2013), in Portugal, the average speed during public transportation is $15.7 \mathrm{~km} / \mathrm{h}$ (STCP, 2013), similar to bicycle trips (Carlson et al., 2014). Moreover, hip-mounted accelerometers may not accurately detect bicycling activities (Welk, 2002) and MVPA during this activities may be underestimated, therefore future studies should explore other devices with improved capability of assessing this behavior. So, more research is needed in order to improve bicycle differentiation in the Portuguese context.

\section{CONCLUSION}

Our study explored the school travel behavior among adolescents providing important data that could assist urban planners and public health professionals in developing initiatives to increase rates of ACS and physical activity among youth.

The main findings suggest that 1) walking is the most frequent means of transport to and from school and a round trip home-school-home represents on average $40 \%$ of recommended daily MVPA; 2) $2.0 \mathrm{~km}$ seems to be a reasonable maximum distance for walking between home and school, so planning and policy efforts should be made in order to achieve this distance; 3 ) cycling is uncommon and to reach higher rates of active travel to school special attention should be given to cycling particularly in trips over $2.0 \mathrm{~km}$; 4) Increasing distance is associated with higher levels of passive transportation to 
school; 5) a distinction should be made between the home-school and schoolhome trips when implementing strategies to increase ACS. 


\section{ACKNOWLEDGEMENTS}

This study was funded by grant: FCT: UID/DTP/00617/2013 and SFRH/BD/70513/2010. 


\section{REFERENCES}

Active Healthy Kids Canada, 2013. Are We Driving Our Kids to Unhealthy Habits? The 2013 Active Healthy Kids Canada Report Card on Physical Activity for Children and Youth, Active Healthy Kids Canada, Toronto.

American public transportation assotiation, 2013. 2013 Public transportation fact book. American public transportation assotiation, Washington, DC.

Black, C., Collins, A., Snell, M., 2001. Encouraging Walking: The Case of Journey-to-school Trips in Compact Urban Areas. Urban Stud 38, 1121-1141.

Carlson, J.A., Jankowska, M.M., Meseck, K., Godbole, S., Natarajan, L., Raab, F., Demchak, B., Patrick, K., Kerr, J., 2014. Validity of PALMS GPS Scoring of Active and Passive Travel Compared to SenseCam. Medicine and science in sports and exercise.

Centers for Disease Control and Prevention, 2002. Barriers to Children Walking and Biking to School - United States, 1999. Morbidity and Mortality Weekly Report 51.

Chillon, P., Ortega, F.B., Ruiz, J.R., Veidebaum, T., Oja, L., Maestu, J., Sjostrom, M., 2010. Active commuting to school in children and adolescents: an opportunity to increase physical activity and fitness. Scandinavian journal of public health 38, 873-879.

Cole, T., Bellizzi, M., Flegal, K., Dietz, W., 2000. Establishing a standard definition for child overweight and obesity worldwide: international survey. BMJ 320, 1240-1243.

Cooper, A.R., Andersen, L.B., Wedderkopp, N., Page, A.S., Froberg, K., 2005. Physical activity levels of children who walk, cycle, or are driven to school. Am J Prev Med 29, 179-184.

Cooper, A.R., Page, A.S., Wheeler, B.W., Griew, P., Davis, L., Hillsdon, M., Jago, R., 2010.

Mapping the walk to school using accelerometry combined with a global positioning system.

Am J Prev Med 38, 178-183.

Davison, K.K., Werder, J.L., Lawson, C.T., 2008. Children's Active Commuting to School: Current Knowledge and Future Directions. Prev Chronic Dis. 5, A100.

Departamento de Avaliação Prospectiva e Planeamento, 2000. Critérios de Reordenamento da Rede Educativa. Ministério da Educação, Lisboa.

Department for Transport, 2014. National travel survey: England 2013, in: Department for Transport (Ed.).

Dessing, D., de Vries, S.I., Graham, J.M., Pierik, F.H., 2014. Active transport between home and school assessed with GPS: a cross-sectional study among Dutch elementary school children.

BMC public health 14, 227.

Duncan, M.J., Badland, H.M., Mummery, W.K., 2009. Applying GPS to enhance understanding of transport-related physical activity. Journal of Science and Medicine in Sport 12, 549-556.

Duncan, M.J., Mummery, W.K., 2007. GIS or GPS? A comparison of two methods for assessing route taken during active transport. Am J Prev Med 33, 51-53.

Evenson, K.R., Catellier, D.J., Gill, K., Ondrak, K.S., McMurray, R.G., 2008. Calibration of two objective measures of physical activity for children. Journal of sports sciences 26, 1557-1565. Faulkner, G.E.J., Buliung, R.N., Flora, P.K., Fusco, C., 2009. Active school transport, physical activity levels and body weight of children and youth: A systematic review. Prev Med 48, 3-8. Feng, T., Timmermans, H.J.P., 2013. Transportation mode recognition using GPS and accelerometer data. Transport Res C- Emer 37, 118-130.

Harten, N., Olds, T., 2004. Patterns of active transport in 11-12 year old Australian children. Australian and New Zealand journal of public health 28, 167-172.

Instituto Nacional de Estatistica, 2012. Recenseamento geral da População, 2001 e 2011. Jacobsen, P.L., 2003. Safety in numbers: more walkers and bicyclists, safer walking and bicycling. Injury Prevention 9, 205-209.

Jensen, S.U., 2008. How to obtain a healthy journey to school. Transport Res A-Pol 42, 475486. 
Kerr, J., Duncan, S., Schipperjin, J., 2011. Using Global Positioning Systems in Health Research: A Practical Approach to Data Collection and Processing. Am J Prev Med 41, 532-540.

Klinker, C.D., Schipperijn, J., Christian, H., Kerr, J., Ersboll, A.K., Troelsen, J., 2014. Using accelerometers and global positioning system devices to assess gender and age differences in children's school, transport, leisure and home based physical activity. The international journal of behavioral nutrition and physical activity 11,8 .

Larsen, K., Gilliland, J., Hess, P., Tucker, P., Irwin, J., He, M., 2009. The influence of the physical environment and sociodemographic characteristics on children's mode of travel to and from school. American journal of public health 99, 520-526.

McCrorie, P.R.W., Fenton, C., Ellaway, A., 2014. Combining GPS, GIS, and accelerometry to explore the physical activity and environment relationship in children and young people - a review. The international journal of behavioral nutrition and physical activity 11, 93.

McDonald, N.C., 2007. Active transportation to school: trends among U.S. schoolchildren, 1969-2001. Am J Prev Med 32, 509-516.

Mota, J., Gomes, H., Almeida, M., Ribeiro, J.C., Carvalho, J., Santos, M.P., 2007. Active versus passive transportation to school-differences in screen time, socio-economic position and perceived environmental characteristics in adolescent girls. Annals of human biology 34, 273282.

National Safe Routes to School Taskforce, 2008. Safe routes to school: a transportation legacy. A national strategy to increase safety and physical activity among American youth., in: Hill, C. (Ed.), NC.

Nelson, N.M., Woods, C.B., 2010. Neighborhood perceptions and active commuting to school among adolescent boys and girls. Journal of physical activity \& health 7, 257-266.

Núcleo de Estudos e Planeamento, 2014. Os velocípedes 2004-2013, in: Unidade de Prevenção Rodoviária (Ed.). Autoridade Nacional para a Segurança Rodoviária, Barcarena, Portugal. Physical Activity and Location Measurement System (PALMS). [http://ucsd-palmsproject.wikispaces.com/] 2013.

Pizarro, A.N., Ribeiro, J.C., Marques, E.A., Mota, J., Santos, M.P., 2013. Is walking to school associated with improved metabolic health? The international journal of behavioral nutrition and physical activity 10,12 .

Pont, K., Ziviani, J., Wadley, D., Bennett, S., Abbott, R., 2009. Environmental correlates of children's active transportation: A systematic literature review. Health \& Place 15, 849-862. Portugal, 2013. Decreto Lei n.o 72/2013 de 3 de setembro, Diário da República, 1. a série Pucher, J., Dill, J., Handy, S., 2010. Infrastructure, programs, and policies to increase bicycling: An international review. Prev Med 50, Supplement, S106-S125.

Santos, M.P., Oliveira, J., Ribeiro, J.C., Mota, J., 2009. Active travel to school, BMI and participation in organised and non-organised physical activity among Portuguese adolescents. Prev Med 49, 497-499.

Schipperijn, J., Kerr, J., Duncan, S., Madsen, T., Klinker, C.D., Troelsen, J., 2014. Dynamic accuracy of GPS receivers for use in health research: a novel method to assess GPS accuracy in real-world settings. FPUBH 2.

Schlossberg, M., Greene, J., Phillips, P.P., Johnson, B., Parker, B., 2006. School Trips: Effects of Urban Form and Distance on Travel Mode. Journal of the American Planning Association 72, 337-346.

Sirard, J.R., Slater, M.E., 2008. Walking and Bicycling to School: A Review. Am J Lifestyle Med 2, 372-396.

Southward, E.F., Page, A.S., Wheeler, B.W., Cooper, A.R., 2012. Contribution of the School Journey to Daily Physical Activity in Children Aged 11-12 Years. Am J Prev Med 43, 201-204. STCP, 2013. Relatório e contas 2013.

Trost, S., Loprinzi, P., Moore, R., Pfeiffer, K., 2011. Comparison of accelerometer cut points for predicting activity intensity in youth. Medicine and science in sports and exercise 43, 13601368. 
Tudor-Locke, C., Ainsworth, B.E., Popkin, B.M., 2001. Active commuting to school: an overlooked source of childrens' physical activity? Sports medicine (Auckland, N.Z.) 31, 309-313. United States Environmental Protection Agency, 2008. Youth Travel to School: Community Design Relationships with Mode Choice, Vehicle Emissions, and Healthy Body Weight in: Torma, T. (Ed.). United States Environmental Protection Agency. Van Dyck, D., De Bourdeaudhuij, I., Cardon, G., Deforche, B., 2010. Criterion distances and correlates of active transportation to school in Belgian older adolescents. The international journal of behavioral nutrition and physical activity $7,87$.

Voss, C., Winters, M., Frazer, M., McKay, H., 2014. Travel to School by Public Transit: Rethinking Active Transportation, 5th International Congress on Physical Activity and Public Health, Rio de Janeiro, Brazil.

Welk, G.J., 2002. Use of Acelerometry based activity monitors to assess physical activity, in: Welk, G. (Ed.), Physical activity assessments for health-related research. Human Kinetics, Champaing, IL.

Wong, B.Y., Faulkner, G., Buliung, R., 2011. GIS measured environmental correlates of active school transport: a systematic review of 14 studies. The international journal of behavioral nutrition and physical activity 8,39 . 


\begin{tabular}{rll}
\hline \multicolumn{1}{r}{ Gender (\%) } & Male & 45 \\
\cline { 2 - 2 } Age (mean/SD) & Female & 55 \\
BMI (Mean/SD) & $15.9 \pm 1.1$ \\
Weight status (\%) & Normal weight & $22.4 \pm 3.5$ \\
\cline { 2 - 3 } & Overweight/obese & 73,5 \\
Daily MVPA (mean/SD) & 26,5 \\
Trips (\%) & Walking & $55.2 \pm 23.5 \mathrm{~min}$ \\
& Bicycle & 57,6 \\
\cline { 2 - 3 } & Vehicle & 16 \\
Trip duration (median) & Walking & 26,4 \\
\cline { 2 - 3 } & Bicycle & $6.5 \mathrm{~min}$ \\
& Vehicle & $5 \mathrm{~min}$ \\
\cline { 2 - 3 } Trip length (median/mean) & Walking & $7.5 \mathrm{~min}$ \\
\hline & Bicycling/bus & $0.34 \mathrm{~km} / 0.53 \mathrm{~km}$ \\
\hline & Vehicle & $0.72 \mathrm{~km} / 1.13 \mathrm{~km}$ \\
\hline \multirow{2}{*}{ Active commuting (\%) } & School/home & $2.82 \mathrm{~km} / 5.84 \mathrm{~km}$ \\
\hline & Other destinations & 9,6 \\
\hline
\end{tabular}

Legend: \%-percentage; SD-Standard deviation; BMI-Body mass index; minminutes; km-Kilometers 


\begin{tabular}{|c|c|c|c|}
\hline & Walking & Bicyling & Vehicle \\
\hline Trips (\%) & 68,8 & 14,4 & 16,7 \\
\hline Trip duration (median) & $14.5 \mathrm{~min}$ & $7.0 \mathrm{~min}$ & $8.0 \mathrm{~min}$ \\
\hline (mean/SD) & $15.4 \pm 1.1 \mathrm{~min}$ & $7.7 \pm 4.0 \mathrm{~min}$ & $9.2 \pm 5.0 \mathrm{~min}$ \\
\hline Trip length (median) & $0.94 \mathrm{~km}$ & $1.08 \mathrm{~km}$ & $2.81 \mathrm{~km}$ \\
\hline (mean/SD) & $1.1 \pm 0.5 \mathrm{~km}$ & $1.2 \pm 0.8 \mathrm{~km}$ & $3.5 \pm 2.7 \mathrm{~km}$ \\
\hline tes in MVPA (mean/SD) & $12.0 \pm 5.6 \mathrm{~min}$ & $2.2 \pm 2.6 \mathrm{~min}$ & $1.3 \pm 1.6 \mathrm{~min}$ \\
\hline Speed (mean/SD ) & $4.1 \pm 0.7 \mathrm{~km} / \mathrm{h}$ & $9.7 \pm 3.0 \mathrm{~km} / \mathrm{h}$ & $21.3 \pm 7.3 \mathrm{~km} / \mathrm{h}$ \\
\hline
\end{tabular}


TABLE 3. DIFFERENCES IN HOME TO SCHOOL VS SCHOOL TO HOME TRIPS BY TRANSPORTATION MODE.

\begin{tabular}{|c|c|c|c|c|c|c|c|c|c|c|c|c|c|c|c|}
\hline \multirow[b]{3}{*}{ length $(\mathrm{km})$} & \multicolumn{5}{|c|}{ WALKING } & \multicolumn{5}{|c|}{ BICYCLING } & \multicolumn{5}{|c|}{ VEHICLE } \\
\hline & \multirow{2}{*}{$\begin{array}{c}\begin{array}{c}\text { Home to } \\
\text { school }\end{array} \\
1,00\end{array}$} & \multirow{2}{*}{$\begin{array}{c}\begin{array}{c}\text { School to } \\
\text { Home }\end{array} \\
1,10\end{array}$} & \multirow{2}{*}{$\begin{array}{c}\begin{array}{c}\text { Sig. (2- } \\
\text { tailed) }\end{array} \\
0,06\end{array}$} & \multicolumn{2}{|c|}{$\begin{array}{l}95 \% \mathrm{Cl} \text { of the } \\
\text { difference }\end{array}$} & \multirow{2}{*}{$\begin{array}{c}\begin{array}{c}\text { Home to } \\
\text { school }\end{array} \\
1,30\end{array}$} & \multirow{2}{*}{$\begin{array}{c}\begin{array}{c}\text { School to } \\
\text { Home }\end{array} \\
1,20\end{array}$} & \multirow{2}{*}{$\begin{array}{c}\begin{array}{c}\text { Sig. (2- } \\
\text { tailed) }\end{array} \\
0,69\end{array}$} & \multicolumn{2}{|c|}{$\begin{array}{l}95 \% \mathrm{Cl} \text { of the } \\
\text { difference }\end{array}$} & \multirow{2}{*}{$\begin{array}{c}\begin{array}{c}\text { Home to } \\
\text { school }\end{array} \\
3,50\end{array}$} & \multirow{2}{*}{$\begin{array}{c}\begin{array}{c}\text { School to } \\
\text { Home }\end{array} \\
3,60\end{array}$} & \multirow{2}{*}{$\begin{array}{c}\begin{array}{c}\text { Sig. (2- } \\
\text { tailed) }\end{array} \\
0,81\end{array}$} & \multicolumn{2}{|c|}{$\begin{array}{l}95 \% \mathrm{Cl} \text { of the } \\
\text { difference }\end{array}$} \\
\hline & & & & $-0,19$ & 0,00 & & & & $-0,29$ & 0,44 & & & & $-1,27$ & 0,98 \\
\hline $\min M V P A(\min )$ & 11,40 & 12,50 & $.035^{*}$ & $-2,30$ & $-0,10$ & 2,80 & 1,30 & $.004 *$ & 0,50 & 2,50 & 1,30 & 0,10 & $.000 *$ & 0,70 & 1,70 \\
\hline duration ( $\mathrm{min}$ ) & 14,00 & 16,50 & $.000 *$ & $-3,80$ & $-1,20$ & 8,20 & 6,90 & 0,15 & $-0,50$ & 3,00 & 9,30 & 9,10 & 0,83 & $-1,90$ & 2,30 \\
\hline
\end{tabular}

Legend: $\mathrm{km}$-Kilometers; minMVPA- minutes in moderate to vigorous physical activity; min-minutes; $\mathrm{Cl}$-Confidence Interval of the difference 
TABLE 4. LOGISTIC REGRESSION ON THE ODDS OF ACTIVE COMMUTING

\begin{tabular}{ccc|ccc}
\multicolumn{3}{c|}{ BOYS } & \multicolumn{3}{c}{ GIRLS } \\
\hline OR & $95 \%$ C.I & P & O.R & $95 \%$ C.I & P
\end{tabular}

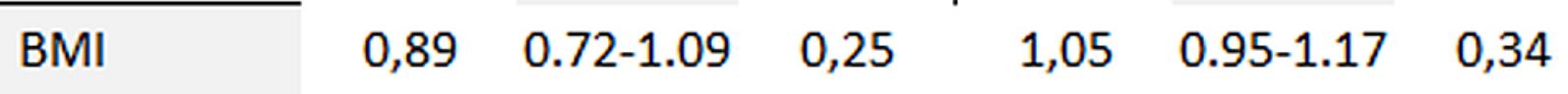

Age $\quad \begin{array}{llllll}1,24 & 0.75-2.08 & 0,40 & 1,00 & 0.61-1.65 & 0,99\end{array}$

$\begin{array}{lllllll}\text { Trips per person } & 1,40 & 1.11-1.79 & 0,01 & 0,97 & 0.88-1.06 & 0,50\end{array}$

$\begin{array}{lllllll}\text { Distance }(\mathrm{km}) & 0,32 & 0.16-0.63 & 0,00 & 0,10 & 0.04-0.25 & 0,00\end{array}$

Legend: O.R.-Odds Ratio; C.I.-Confidence Interval; BMI- Body mass index; Km* School is included in the model as fixed effect 
FIGURE 1. PERCENTAGE OF TRIPS PER TRANSPORTATION MODE ACROSS THE WEEK

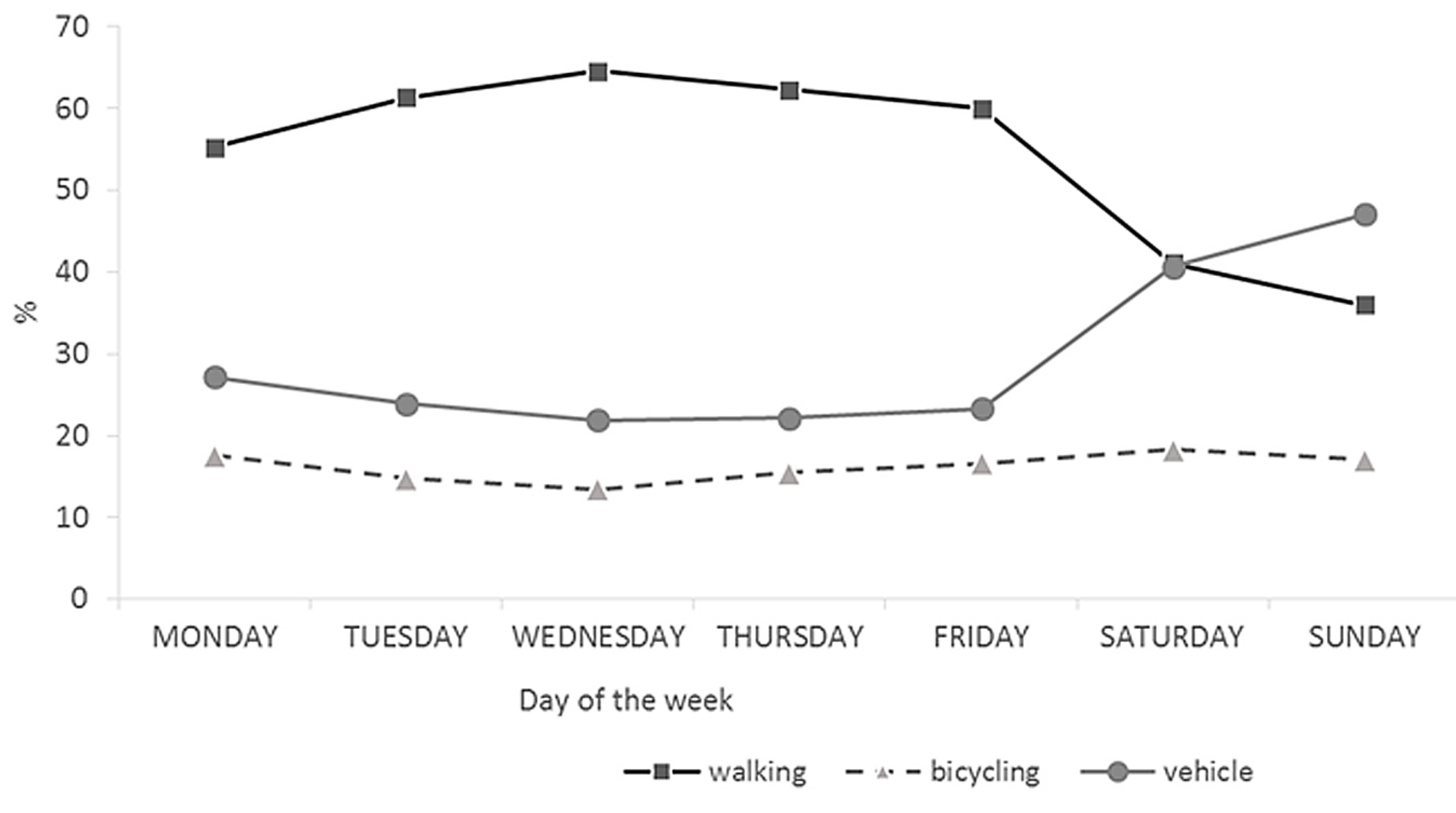




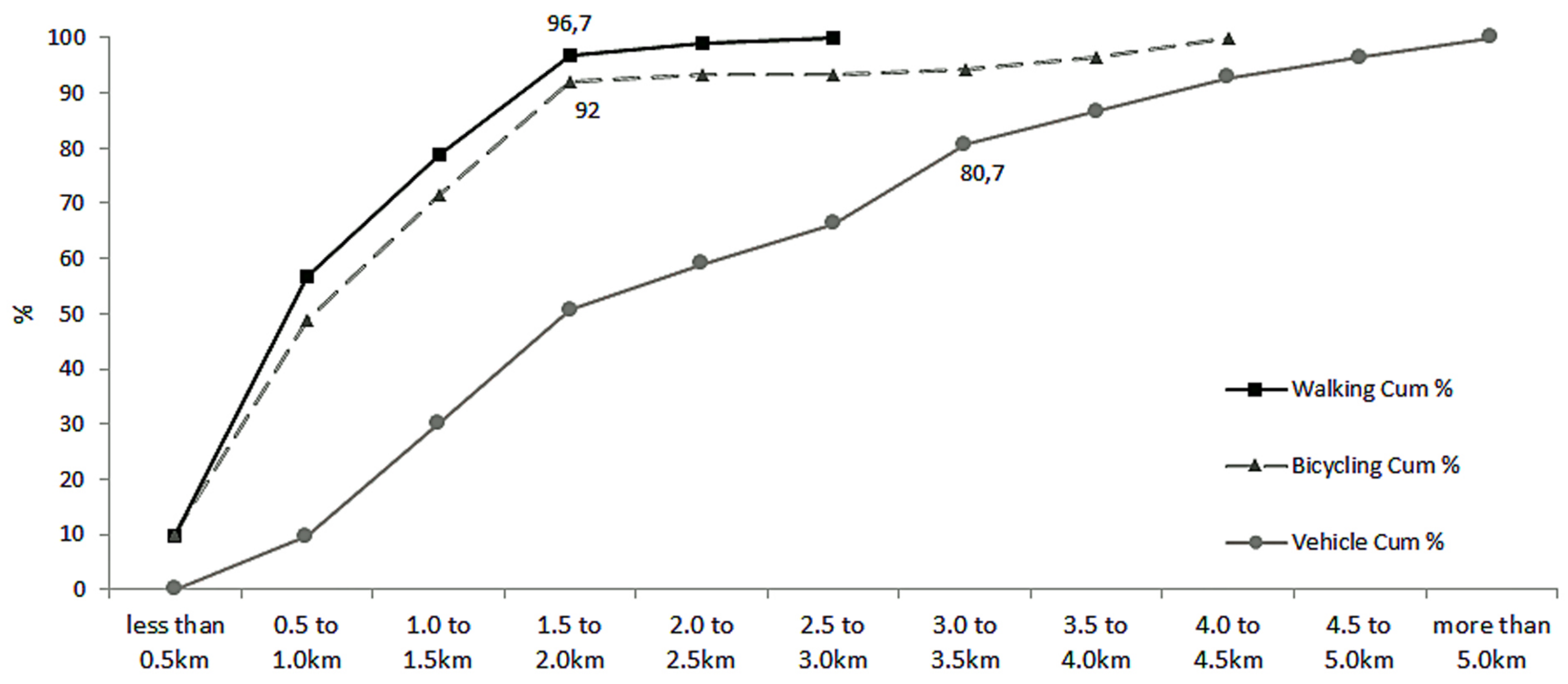

Legend: km-Kilometers; Cum \%-cumulative percentage 
90

80

70

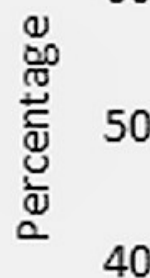

30

20

10

0
76,2

60,4

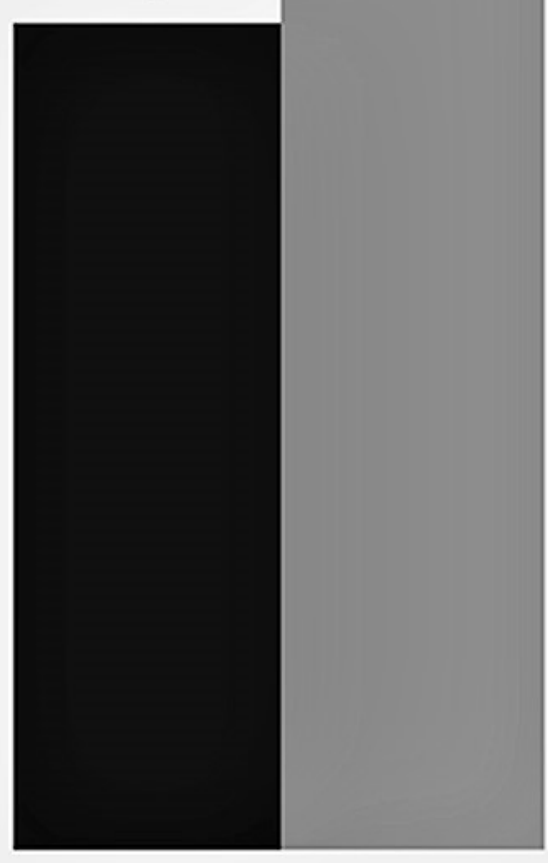

Walking
18,2

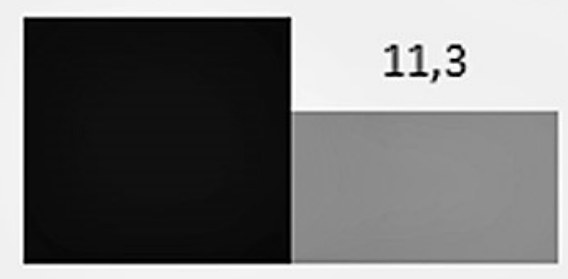

Bicycling
21,5

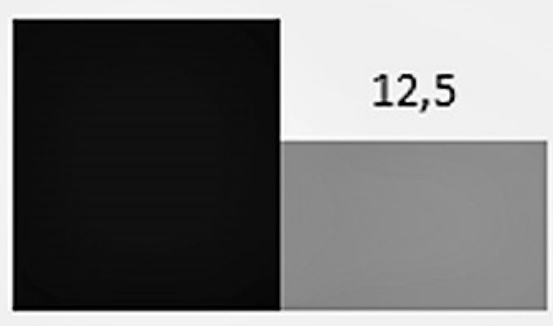

Vehicle 